\title{
Onorden
}

Nordic Council of Ministers

\section{Sustainable Nordic Welfare}

- a programme for new welfare solutions for people in the Nordic region

Status report for the Nordic Prime Ministers Summer Meeting 27 May 2014

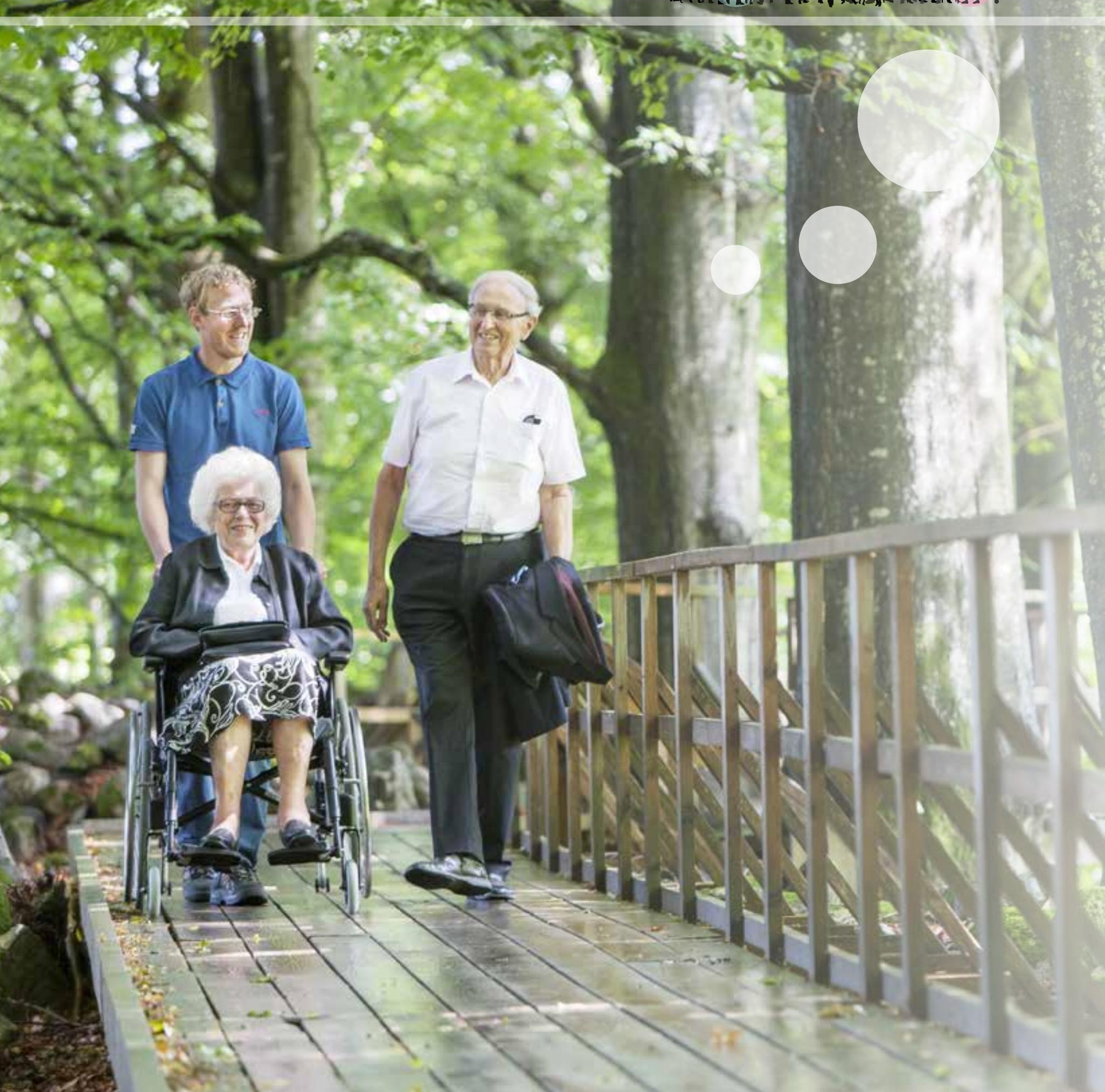


- a programme for new welfare solutions for people in the Nordic region

http://dx.doi.org/10.6027/ANP2014-736

ISBN 978-92-893-2817-3

ANP 2014:736

(C) Nordic Council of Ministers 2014

Layout: Jette Koefoed

Photo: Christiaan Dirksen

Print: Rosendahls-Schultz Grafisk

Translation: Leslie Walke

Copies: 200

Font: Meta LF

Paper: Munken Polar

Printed in Denmark

\section{Nordic co-operation}

Nordic co-operation is one of the world's most extensive forms of regional collaboration, involving Denmark, Finland, Iceland, Norway, Sweden, and the Faroe Islands, Greenland, and Åland.

Nordic co-operation has firm traditions in politics, the economy, and culture. It plays an important role in European and international collaboration, and aims at creating a strong Nordic community in a strong Europe.

Nordic co-operation seeks to safeguard Nordic and regional interests and principles in the global community. Common Nordic values help the region solidify its position as one of the world's most innovative and competitive.

\section{Nordic Council of Ministers}

Ved Stranden 18

DK-1061 Copenhagen K

Telefon (+45) 33960200

www.norden.org 


\title{
Sustainable Nordic Welfare
}

\author{
- a programme for new welfare solutions for people in the Nordic region
}

\section{Background \\ The Sustainable Nordic Welfare programme implements the Nordic prime ministers' request to the Nordic ministers for health and social affairs to prepare tangible proposals for further development of the Nordic co-operation on health. At the Nordic prime ministers' meeting on 10 June 2012, the prime ministers asked the health ministers to review, in particular, the Nordic co-operation on testing of new drugs and treatments, co-operation on highly- specialised functions, and research on health and welfare.}

The Sustainable Nordic Welfare programme applies for the period 2013-2015. In addition to developing and giving a tangible form to the Nordic health cooperation, the programme also involves tangible initiatives in the health and labour market areas. The two councils of ministers with main responsibility are the Nordic Council of Ministers for Education and Research (MR-U) and the Nordic Council of Ministers for Health and Social Affairs (MR-S).

The aim of Sustainable Nordic Welfare is to contribute tangible and innovative solutions and tools to the Nordic governments for managing welfare policy challenges. The solutions will contribute to increased quality and equality in education, work and health care. This will be attained by joint financing of tangible initiatives and by building Nordic platforms for dialogue and exchange of experiences.

In 2013 and 2014, approximately DKK 50 million has been allocated to Nordic Sustainable Welfare initiatives from the priority budget of the Nordic Ministers for Co-operation (including DKK 14 million from the presidency component of the priority budget) and the professional sector's own budgets.
Sustainable Nordic Welfare will be implemented through tangible initiatives and activities in three focus areas:

1. Education and work for welfare

2. Research for welfare

3. Infrastructure for welfare

The programme is a complement to the work of the Nordic countries on renewing and developing welfare at national level. Great emphasis is therefore placed on involving key decision-makers in the countries. The countries have also appointed national contact persons for the programme. Great emphasis is placed on seeing the Nordic processes and projects in relation to national and European processes and projects.

In August 2013, a launch conference was arranged for contact persons, project managers, members of the committees of senior officials, and other Nordic players. In spring 2014, the secretariat held national seminars in each country, where the programme and the individual projects were presented and discussed. In addition, a mid-term conference is planned for September 2014. The conference will focus on preliminary results and knowledge transfer.

One important part of the work in 2014 and 2015 is to show and disseminate the results, and to follow up on the independent study of future Nordic health cooperation initiated by the Nordic ministers for health and social affairs, together with the Secretary General of the Nordic Council of Ministers, in August 2013. 

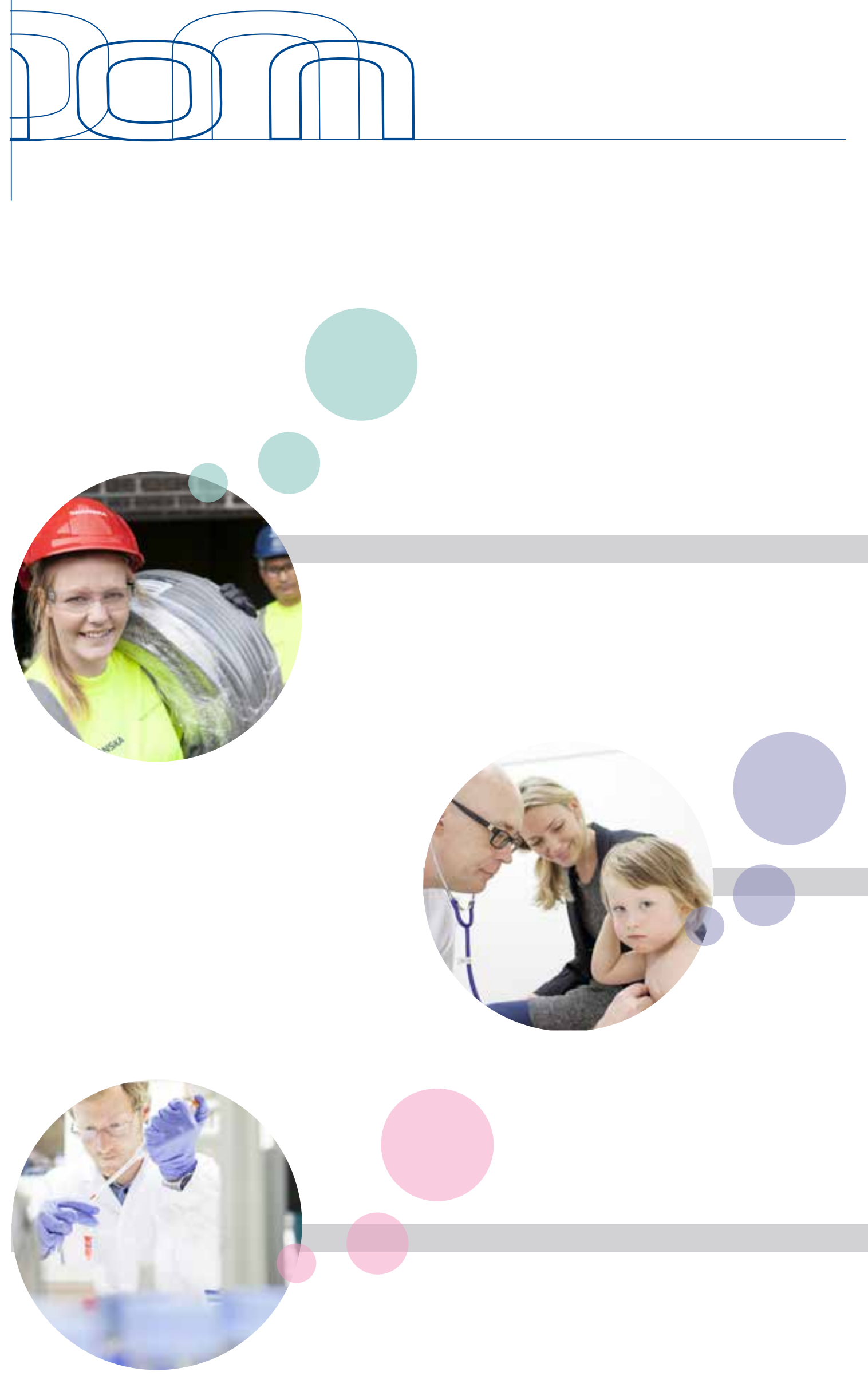


\section{Summary of the work under Sustainable Nordic Welfare}

\section{Sustainable Nordic Welfare will be implemented through tangible initiatives and activities in three focus areas:}

\section{Focus Area 1: Education and work for welfare}

Measures and activities in Focus Area 1 will help to:

- Ensure that education leads to work

- Secure supply of skills and expertise in the health and care sector

Responsibility: The ministers for education and research, in collaboration with the ministers for labour and the ministers for health and social affairs

\section{Focus Area 2: Research for welfare}

Measures and activities in Focus Area 2 will help to:

- Promote research and development of knowledge and models that can contribute to welfare for everyone

Responsibility: The ministers for health and social affairs, in collaboration with the ministers for education and research

\section{Focus Area 3: Infrastructure for welfare}

Measures and activities in Focus Area 3 will help to:

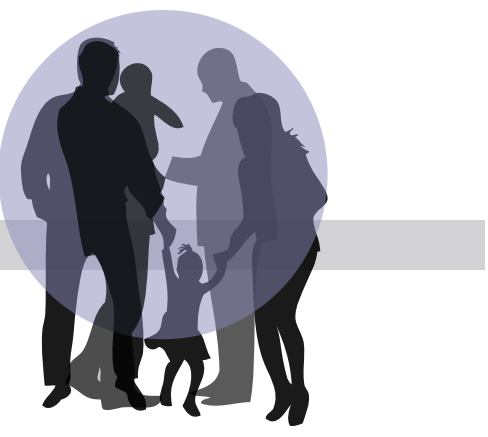

- Develop and secure the quality in health care

Responsibility: The ministers of health and social affairs, in collaboration with the ministers for education and research. 


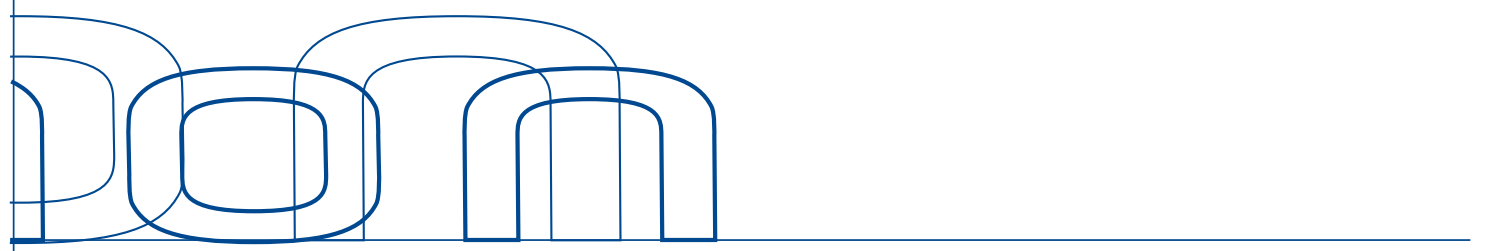

Focus Area 1: Education and work for welfare

Measures and activities in Focus Area 1 will help to:

- $\quad$ Ensure that education leads to work

- Secure supply of skills and expertise in the health and care sector

Responsibility: The ministers for education and research, in collaboration with the ministers for labour and the ministers for health and social affairs

High dropout rates from upper-secondary and vocational training programmes, and youth unemployment in relation to demographic changes, are major challenges for the Nordic welfare model. It is important that young people find work, both to finance welfare in the Nordic countries and also to secure a meaningful life for the individual.

The report State of the Nordic Region 2013 (Nordregio) shows that the number of elderly people in the Nordic region grew by $2.8 \%$ in the period 2008-2013 and that 27.9 of every 100 individuals are over 65 . This is higher than the EU average of 26.8 .

The challenges on the labour market vary between the countries. Finland's greatest challenge is the number of people on long-term sick leave. Sweden's is youth unemployment. Norway tops the statistics for people on sickness benefit or activity compensation with $9 \%$ (the average for the Nordic countries is 6.9\%). The increase is seen particularly among young people.

The following results have been attained halfway through the programme in Focus Area 1. Education and work for welfare:

\section{Learning at the workplace}

To meet the challenges of securing apprenticeships and internships for people on vocational training, and to improve the quality of workplace-based training, the Nordic Council of Ministers has started a project on learning at the workplace.

The project, which is led by the Swedish National Agency for Education, will facilitate co-operation between local players and colleagues in other Nordic countries to exchange experiences, thereby stimulating their own development work regarding learning at the workplace. By following the local development work from national and Nordic levels, the project will contribute to learning and development of workplace learning.

During the project period, meeting places are arranged in each country and the Faroe Islands and Åland, with approximately 100 local and Nordic participants. The meeting places contribute to Nordic skills development between participants from different sectors, schools, authorities and organisations that do not normally have contact with each other. A final conference will be arranged in Sweden in September 2015, and a final report will be prepared.

\section{Nordic knowledge bank about school dropout}

Young people's decreasing opportunities to enter the labour market, the growing youth unemployment and early retirement among young people, and the increasing proportion of NEETs (Not in Education, Employment or Training) in every year group, comprises a serious challenge for the sustainability of the Nordic welfare model. Up to $20-40 \%$ of all young people who start an upper-secondary or vocational training programme in the Nordic region do not complete their education within the designated period or the two subsequent years.

The aim of the Nordic knowledge bank about dropout is to show and disseminate relevant knowledge about effective preventive measures and other methods that help more young people complete their education. The knowledge bank was opened in autumn 2013 at the address www.kunnskapsbanken. org, and is continually presented at various events in the Nordic countries. The work is led by the Nordic Centre for Welfare and Social Issues. 


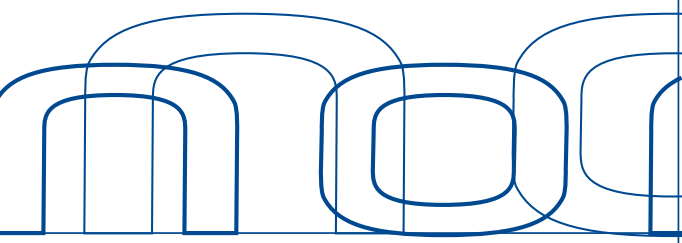

Mobility and recognition of professional qualifications in the Nordic region

The Nordic region is an open educational and job market area, and there is ample opportunity for students and others to study and work across borders. In order to increase mobility and reduce border obstacles, continual work is needed to simplify procedures for recognition of educational qualifications and expertise. In order to promote greater mobility, the Nordic Council of Ministers has reviewed the Nordic countries' procedures and requirements for approval of Nordic applications to regulated professions. The report Regulated Vocational and Welfare Professions in the Nordic Region also shows similarities and differences between health and care educational programmes in the Nordic countries. This helps to clarify levels of expertise, which in turn can promote greater mobility.

The work is being monitored by the education, health, labour and business sectors, and the newlyformed Labour Mobility Council that is working to ensure freedom of movement in the Nordic region. The Nordic work is coordinated with the national work in implementation of the EU's revised directive on recognition of professional qualifications. In accordance with national requests, the Nordic Council of Ministers in 2014 will be gathering professional advisors from the responsible authorities in the respective countries. The aim will be to share experiences and knowledge about work in implementing the directive, and to promote the Nordic perspective in the continued work to secure a transparency and simplification of the directive.

\section{Entrepreneurship in education}

The future competitiveness and welfare of the Nordic region is partly dependent on the ability of the labour force to think innovatively, see opportunities and convert ideas to solutions. Therefore, the Nordic educational systems must stimulate the ability of pupils and students to work creatively and flexibly, take initiative, and develop innovative solutions to society's problems. One objective of the project is to disseminate the Nordic entrepreneurial culture in schools, and to motivate compulsory schools to engage in and practice entrepreneurial teaching. The aim is that the young people will be better prepared for the future labour market, and that they can contribute to innovations and future welfare solutions.
Ahead of a conference in November 2013 on entrepreneurship in schools, the magazine Nårjeg bliver stor... (When I grow up...) was produced. The magazine contains examples of how schools in the Nordic region, in a topical and tangible way, work with entrepreneurship in schools. The magazine has been distributed to schools to provide inspiration. In spring 2014 various players in the countries are working together to highlight further requests and needs that can strengthen entrepreneurship in compulsory schools and in teacher training programmes in the Nordic region, with the aim of implementing these in autumn 2014 and in 2015.

\section{Other initiatives started}

Work is taking place to increase knowledge about initiatives in the Nordic region to promote social entrepreneurship and social innovation in the inclusion of vulnerable groups in the labour market and in society. Furthermore, an analysis of the Nordic welfare model is nearing completion. The analysis reviews the Nordic welfare model's earlier and current performance, future challenges and possible solutions. The analysis is being presented at the anniversary conference of the Nordic ministers of employment, held in Iceland in May 2014.

A research co-operation in the welfare professions is starting in spring 2014. Its aim is to contribute to greater knowledge and exchange of experiences within research on welfare professions, and to give good examples of how new knowledge is transferred from research to education and implementation in practice. In addition, a study is being carried out that will make proposals relating to future challenges, needs and visions for the Nordic professional and apprenticeship system. The report is a follow up of the Nordic labour market meeting that was arranged in Sweden in May 2013.

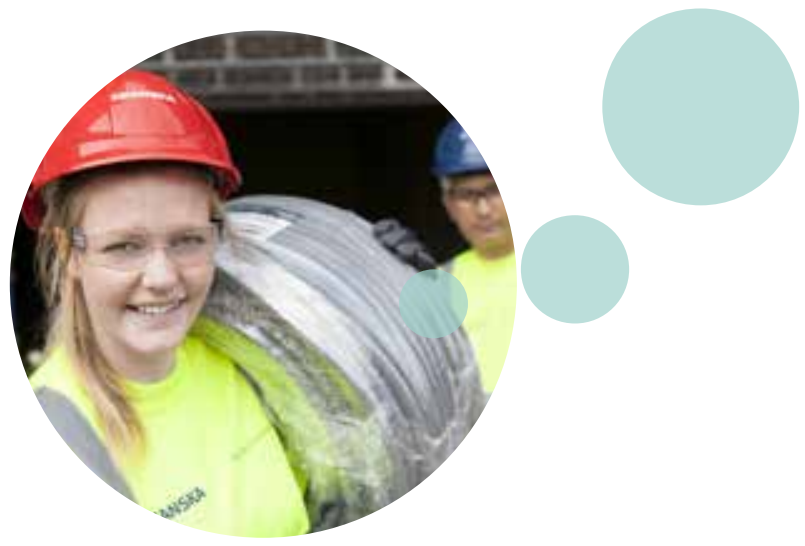




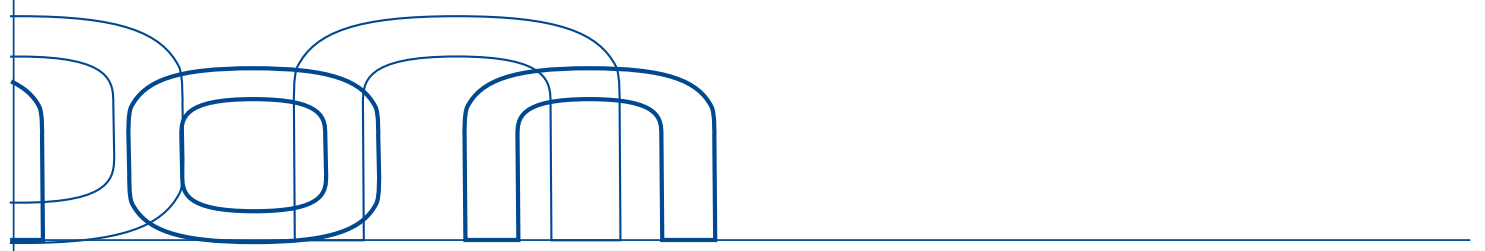

Focus Area 2: Research for welfare

Measures and activities in Focus Area 2 will help to:

- Promote research and development of knowledge and models that can contribute to welfare for everyone

Responsibility: The ministers for health and social affairs, in collaboration with the ministers for education and research

Quality of life in the Nordic region is one of the highest in the world. The factors used to measure quality of life include health, job security and gender equality. Despite this, there is a need for crossdisciplinary knowledge about underlying causes of inequality in health and welfare in the Nordic region. Welfare research concerns how people live their lives and how various factors can explain people's living conditions.

If the Nordic countries are to continue to top surveys of quality of life in the future, it is important to further develop our welfare societies in a number of areas. This applies not least in the health area, where there is potential for greater Nordic co-operation and thereby greater Nordic added value.

\section{The following results have been attained halfway through the programme in Focus Area 2. \\ Research for welfare:}

\section{Research on social inequality in health and welfare}

The Nordic Council of Ministers is funding Nordic research on social inequalities in health and welfare. The research is examining the underlying causes of the unequal distribution of health and welfare in today's Nordic societies in terms of the points of intersection between gender, social class, ethnicity, regional differences, etc.

The Nordic Council of Ministers has allocated funding to a call for applications for research funds that will be administered by NordForsk. The call will take place in summer 2014 within the framework of NordForsk's five-year research programme on health and welfare, which has a total budget of approximately NOK 125 million. The aim of the project is to intensify and strengthen Nordic research collaboration on socioeconomic differences in health and welfare. The research findings will form the basis of measures that can help to reduce these differences and thereby lead to improved health and welfare in the Nordic region.

\section{Report on the future Nordic co-operation on health (the Könberg Report)}

Together with the Secretary General of the Council of Ministers, the Nordic ministers for health and social affairs have initiated a study of how the Nordic co-operation on health can be developed and strengthened in the next 5-10 years. The work will result in a short report with focus on recommendations and tangible proposals for solutions.

The former Swedish minister, Bo Könberg, was given the task of writing the report, which was handed over to the Nordic ministers for health and social affairs in June 2014.

\section{Other initiatives started}

A Nordic report that is examining models for recruitment and retention of employees in the health sector is nearing completion. A decision on a possible follow-up will be made in autumn 2014. Another extensive initiative is Nordic Welfare Watch, which is led by the Icelandic presidency in 2014. The aim is to investigate the consequences of crises for the Nordic welfare societies.

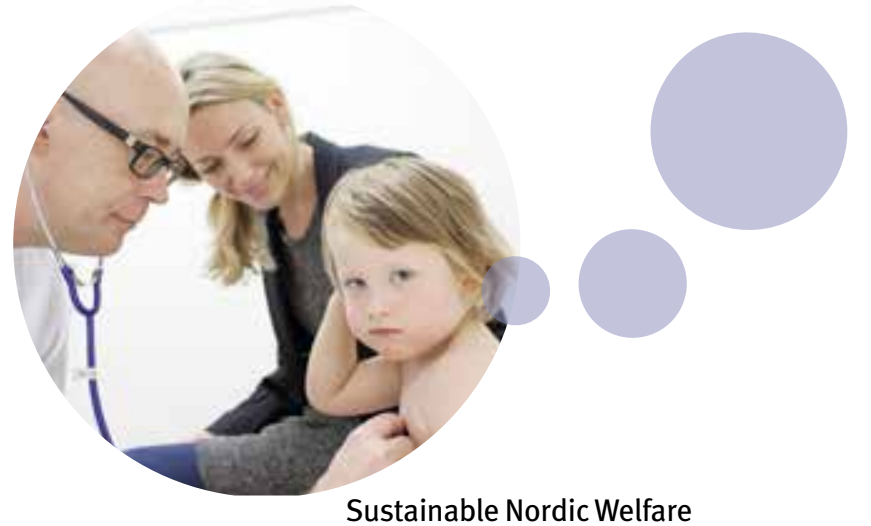




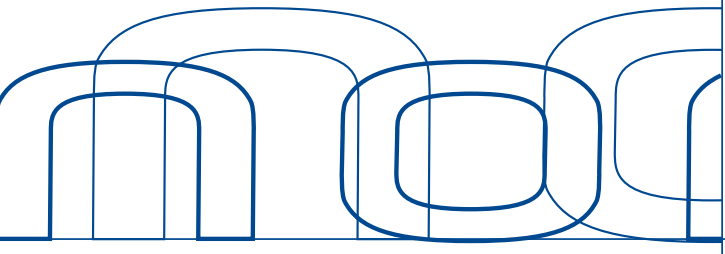

Focus Area 3: Infrastructure for welfare

Measures and activities in Focus Area 3

will help to:

- Develop and secure the quality in health care

Responsibility: The ministers of health and social affairs, in collaboration with the ministers for education and research.

Research that enables high-quality, patient-safe and cost-effective health care is vital for the development of welfare. The Nordic region, with its 26 million inhabitants and with great similarities between the populations, and with traceable data in the systems, is a gold mine for researchers. In order to use the available information, there is a need for greater coordination of social registers, biobanks, testing of drugs and treatments, not only between the Nordic countries but also between the registers. New technology is also needed to meet future needs in the welfare sector.

The results from the focus area will contribute to better information about how to prevent diseases, find more efficacious drugs and new treatment methods, and efficient technology.

\section{The following results have been attained halfway through the programme in Focus Area 3. Infrastructure for welfare:}

\section{Nordic co-operation on biobanks, health registers and social registers}

In the Swedish presidency in 2013, focus was placed on improving interaction between the research infrastructure in the Nordic countries; examples are a number of expert seminars and conferences concerning research infrastructure arranged by, for example NordForsk, the Swedish Presidency, and the Nordic Council of Ministers.
The overall objective of the project is to strengthen Nordic co-operation in research relating to registers, biobanks and interventions, through improved access to Nordic data sources for research. In order to attain this, existing obstacles that make it difficult to share research data over national borders must be overcome. These obstacles may be ethical, legal, technical and organisational.

The project will follow up the tangible recommendations of the NordForsk advisory group 'NORIA-net Register' and the action points presented during the session on health and welfare at the conference "Joint Nordic Focus on Research Infrastructures - Looking to the Future' held in November 2013; some of these have already been initiated:

- Offer a co-operation platform for Nordic statistical agencies, managers of national health registers and other registers with the aim of strengthening Nordic research.

- In collaboration with the Nordic Council of Ministers, investigate ways in which mutual approval of ethical review permits may be attained between the Nordic countries, and discuss models for informed consent.

- Monitor the possibilities for Nordic collaboration that could arise during ongoing revision of European legislation concerning data protection, clinical trials, and copyright. If necessary, and after consultation with the Nordic Council of Ministers, take measures.

- Support development of technical solutions for safe data management, for example through the Nordic e-Infrastructure Collaboration (NeIC).

- In collaboration with the Nordic Council of Ministers, investigate the possibilities for creating solutions similar to the Danish system for health data in other Nordic countries.

- Call for applications for funding for research projects and educational programmes to support Nordic register-based research within the NordForsk programme for health and welfare. 


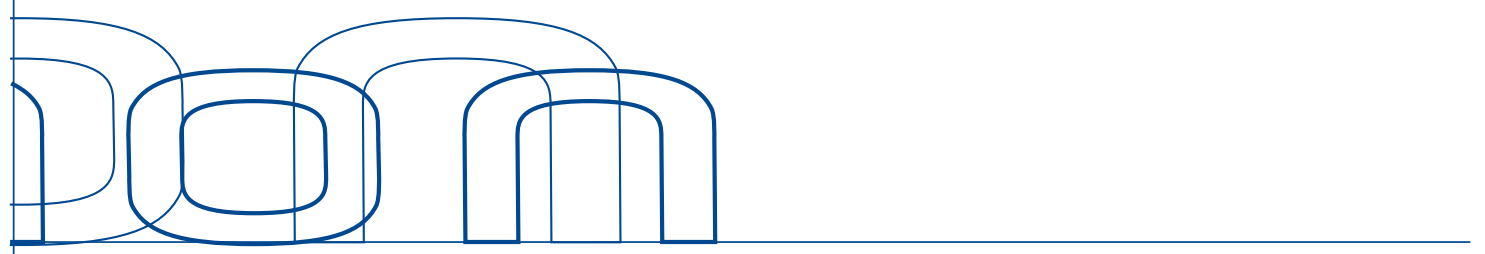

The target group of the project is the Nordic research community, which can more easily use existing data sources. However, the project, which is led by NordForsk, will involve several national and Nordic key players. These players include the national research councils, ethical review committees, government statistical agencies, and data protection authorities. This also includes a number of Nordic stakeholders: Nordic e-Infrastructure Collaboration (NeIC), the Nordic Committee on Bioethics, and existing Nordic infrastructure networks (e.g. Nordic Trial Alliance, Nordic Biobank Network).

\section{Nordic co-operation on clinical studies}

Clinical studies, i.e. investigation of the effect of a pharmaceutical or a treatment method, have decreased dramatically in the Nordic region in the past thirty years. The Nordic Council of Ministers, via NordForsk, is working to simplify the processes for implementing clinical studies across the Nordic countries, with the aim of increasing the number of clinical studies in the Nordic region. Clinical studies are an important component in introducing new methods and treatments for patients.

Nordic Trial Alliance (NTA) aims to increase the Nordic co-operation in, for example, testing of new treatment methods and drugs in order to promote quality, patient safety and health. NTA is currently establishing a database containing current Nordic studies that will facilitate recruitment of patients. This database will be reached via nta.nordforsk.org.

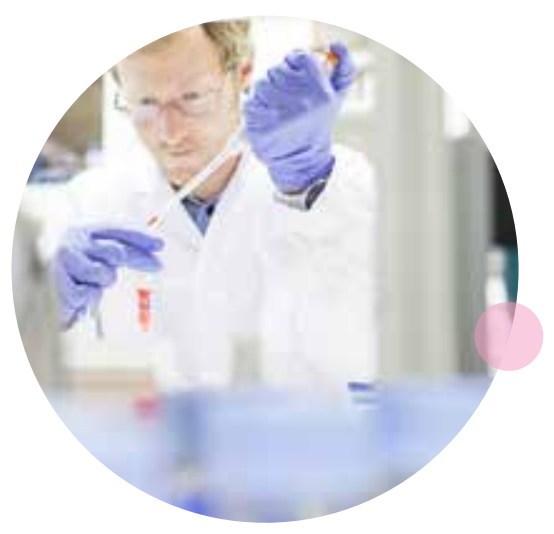

In January 2014, NTA opened a call aimed at funding one or two pilot projects that will show the Nordic added value in expanding national clinical studies into Nordic studies. Decisions on which projects will receive funding will be made in June 2014 .

\section{Nordic co-operation on highly-specialised treatments}

Within health care today, there are highly-specialised functions where, because of their rarity, complexity, and/or shortage of resources, it can be hard to maintain expertise, experience, routine and technology. Co-operation on highly-specialised treatments, which is led by the Norwegian Directorate of Health, is aimed at developing and describing models for Nordic co-operation. The models are developed through specified pilot studies in three areas: Nordic quality registers, common Nordic guidelines/processes for diagnostics and treatment in specific professional areas, and organisation and structuring of the professional co-operation for skills development, promotion of treatment quality, and patient safety.

In 2013, four pilot studies were started:

- A Nordic quality register for spinal cord injuries (led by St. Olav's Hospital, Trondheim, Norway).

- A Nordic quality register for arthroplasty in wrist and ankle joints (led by Haukeland University Hospital, Bergen, Norway).

- Co-operation in paediatric surgery with focus on congenital gastro-intestinal disorders (led by Odense University Hospital, Denmark).

- Joint training of specialists in pre-natal diagnostics, with focus on treatment of foetus in the womb (led by Rigshospitalet in Copenhagen, Denmark). 
Work is under way to start a further three pilot projects in the area of common Nordic guidelines/processes:

- Guidelines for treatment of retinoblastoma (cancer in the eye that is often congenital) (led by St. Erik's Hospital, Stockholm, Sweden).

- Guidelines for surgical corrective treatment of tetraplegia (which involves loss of function in arms, torso, pelvic organs and legs caused by damage to the neck section of the spinal cord) (led by Haukeland University Hospital, Bergen, Norway).

- Guidelines for diagnostics and medical treatment of transsexual people (led by Oslo University Hospital, Norway).

The project also aims to develop descriptions of how Nordic co-operation in highly-specialised treatments can occur within the frameworks of the countries' laws and policies, and how an established cooperation can be secured within existing economic and organisational frameworks. These descriptions will be made accessible for other professional areas that see the need for Nordic co-operation, with the aim of securing professional development, quality and patient safety in their own area.

\section{Other initiatives started}

In order to strengthen the Nordic municipalities' work on welfare technology, in spring 2014 the Nordic Centre for Welfare and Social Issues is starting a project to increase the implementation capability and skills level of municipalities in relation to welfare technology, strengthen the relationship between supply and benefits, strengthen the common Nordic market, and support existing national strategies. 


\section{norden}

Nordic Council of Ministers

Ved Stranden 18

DK-1061 Copenhagen K

www.norden.org

\section{Sustainable Nordic Welfare}

- a programme for new welfare solutions for people in the Nordic region

The Sustainable Nordic Welfare programme implements the Nordic prime ministers' request to the Nordic ministers for health and social affairs to prepare tangible proposals for further development of the Nordic co-operation on health. At the Nordic prime ministers meeting on 10 June 2012, the prime ministers asked the health ministers to review, in particular, the Nordic co-operation on testing of new drugs and treatments, co-operation on highly-specialised functions, and research on health and welfare.

The Sustainable Nordic Welfare programme applies for the period 20132015. In addition to developing and giving a tangible form to the Nordic health co-operation, the programme also involves tangible initiatives in the health and labour market areas. The two councils of ministers with main responsibility are the Council of Ministers for Education and Research (MR-U) and the Council of Ministers for Health and Social Affairs (MR-S).

www.norden.org/welfare 